DOI: $10.1515 / \mathrm{rpp}-2017-0010$

Doctoral Candidate, OLEKSANDR SHUMSKYI

Zaporizhzhia National University

Address: 66 Zhukovskoho St., Zaporizhzhia, 69600, Ukraine

E-mail: oll123@meta.ua

\title{
THE PROBLEM OF LINGUISTIC SELF-EDUCATION IN WORLD THEORY AND PRACTICE (HISTORICAL AND PEDAGOGICAL ASPECTS)
}

\begin{abstract}
In the paper it has been grounded that under the conditions of forming postindustrial epoch, which is characterised by the processes of globalisation and informatisation, there exists a social demand for the specialists who have a formed preparedness for continuous self-education, including linguistic self-instruction. This presupposes developing innovative and strategic thinking as well as realising the objective necessity of continuous enhancing of their proficiency level, which is a key factor of interaction with dynamic and changeable professional environment with rapid obsolescence of knowledge, constant technological advancement, etc. It has been proved that nowadays the role of self-education, as the instrument of forming highly-qualified professionals with sufficient knowledge of foreign languages, is always growing in different countries. Therefore, educators are continually facing the task of improving the theoretical and methodological base of teaching students to be autonomous in their studies. It has been substantiated that, in view of the principle of continuity in science, introducing any innovations into the learning process in linguistic self-education should be preceded by the profound studying of the pedagogically valuable theoretical and practical experience, gained by the previous generations of researchers. Thus, the retrospective analysis of basic historical milestones of evolving the phenomenon "linguistic self-education" has been conducted and its results have been presented in this work.

Key words: postindustrial epoch, retrospective analysis, self-knowledge, selfinstruction, adult learning, learner autonomy, linguistic self-education, self-access centres.

\section{INTRODUCTION}

Under the conditions of globalisation, continual renewal of technologies and knowledge has become a distinctive feature of present-day information society. This stipulates the demand for the specialists of a new type, that is, with particular personality qualities, faculties and skills, which would ensure their sustained progress, social mobility and flexible adapting to all transformations in today's ever-changing world. In light of this, lifelong self-education, as an effective instrument for everlasting all-round selfdevelopment, should become one of the highest values in the individual's life.

On the basis of analysing the current state of higher education in different countries we can conclude that there exists a steady trend toward general self-instruction, including linguistic self-learning, as a means of training a competitive professional with innovative and strategic thinking, who is capable of overcoming all challenges of the postindustrial epoch. In this context, despite the presence of extensive theoretical and methodological base of forming the students' preparedness for persistent linguistic selfeducation, in accordance with the principle of continuity in science, we consider that it is
\end{abstract}


relevant to study and rethink the evolution of foreign language self-study from a presentday perspective.

\section{THE AIM OF THE STUDY}

The aim of the paper is to systematise and generalise the historical theoretical and practical experience of developing linguistic self-education as a separate avenue of pedagogical research in various countries of the world.

\section{THEORETICAL FRAMEWORK AND RESEARCH METHODS}

Doing this research has presupposed analysing the works dedicated to studying pedagogically valuable experience in the history of pedagogy (C. Goldin, A. Howatt, K. Matiichuk, B. Noonan, I. Sydorenko); to considering historical and social background of self-education (N. Aoki, S. Dneprov, H. Holec, D. Little, W. Littlewood, P. Riley, O. Shuklina, M. Skatkin, R. Smith, A. Wenden); to investigating the modern theoretical and practical aspects of organising self-instruction at universities of a number of countries, in particular, in the UK (O. Palekha), in the USA (I. Sulim-Karlir), in France (L. Ziaziun), etc.

Such methods as analysis, synthesis, comparison, systematisation and generalisation of the data on the main historical milestones of the evolution of linguistic self-education from the earliest times till today form the basis of this research.

\section{RESULTS}

For many centuries, in the world pedagogical theory and practice the linguistic self-education as such had not been regarded as a separate educational phenomenon because the question was only on the applied significance of foreign language learning. In different historic periods, starting from the earliest times, despite the absence of the institutional base for studying foreign languages, there had always been people who mastered them on their own. Thus, in the golden age of culture in Ancient Greece, Rome, Egypt, Syria there was the necessity of independent acquiring foreign language knowledge due to rapid extension of commercial relations between these countries, and in that case foreign languages had served as the means of international dialogue.

We should specify that in the context of our research we consider linguistic selfeducation as a holistic pedagogical category which is an integral constituent of a broader notion "self-education". In this respect, we think that it is relevant to trace the origins and main milestones of the evolution of continuum "self-knowledge - self-education linguistic self-education".

The analysis of prominent antique philosophers' and Oriental thinkers' views on the essence of self-education enables us to conclude that ancient science, which linked selfeducation with self-knowledge (Aristotle, Democritus, Socrates); with moral self-perfection (Laozi, Plato); with the search for truth and new knowledge (Seneca), formed the scientific basis of the self-education theory. In the Middle Ages there prevailed the religious type of foreign language self-learning as they were mainly learned for translating sacred writings. Along with that there existed various forms of secular linguistic self-instruction, which was chiefly realised in communication as well as in reading and writing activities. The Renaissance era saw profound rethinking of the content and significance of self-education. In those times the principle of students' independence in comprehending the world was first formulated, and the attempt to disclose the methodological fundamentals of self-education was made (J. Komensky, M. Montaigne, T. More, J. Pestalozzi). The ideas of outstanding thinkers and teachers of the age of Enlightenment played a crucial role in further development of the self-education theory and its spreading. In that period self-education was interpreted as independent activities of mass proportions and peculiar to entire social groups (A. Diesterweg, I. Kant, J.-J. Rousseau). Rapid development of theoretical 
knowledge not only enhanced the status of self-education and triggered its considerable dissemination, including the sphere of foreign language learning, but also favoured the elaboration of specific methods of linguistic self-educational activities. Thus, in the $16^{\text {th }}$ century there appeared the tandem method of foreign language studying which was accorded wide recognition worldwide in the second half of the $20^{\text {th }}$ century. At the end of the $18^{\text {th }}$ century British educators A. Bell and J. Lancaster proposed the method of mutual instruction which gave birth to the Monitorial system. According to it, senior students, who had already learned the material by themselves under the teacher's guidance, trained other students, following the teacher's instructions. It is appropriate to mention that nowadays this method is actively applied in linguistic self-education. In the second half of the $19^{\text {th }}$ century intensive industrial growth, increasing number of scientific literature in national languages, improving communication lines and unprecedented broadening of international trade relations caused the need for highly educated specialists with foreign language knowledge, which gave a new look at the significance of foreign language self study. The emergence of printed teach-yourself textbooks in foreign languages was of great importance for mass development of linguistic self-education. Thus, in 1856 in Germany the first French self-taught was published and subsequently there emerged the similar teach-yourself textbooks in many other languages. Those textbooks were based on the textual-translation method of foreign language self-learning, which was worked out by German linguists Ch. Toussaint and G. Langenscheidt.

In the 20th century, after gradual eliminating the consequences of the World War II, changes in political, ecomomic and cultural picture of the world due to opening borders, slackening the "Iron Curtain", emerging numerous international organisations, etc., caused the intensification of interstate relations in all the spheres of social life. As a result of this there arose an urgent requirement of accelerated foreign language training not only students but also adults, in particular, politicians, entrepreneurs, lawyers, teachers, etc. Because of this, in the post-war period the status of foreign languages altered, because then it was viewed in the socio-anthropological sense, that is, as the instrument of international and intercultural dialogue. That perspective was completely different from the classical perception of the foreign language, which used to be regarded as the subject of high culture, general erudition; as the attribute of the personality's scholarship; as the means of refining the human's mind, taste and manners; as the intellectual constituent of forming the civilisation in whole (Onions, 1944).

At the end of 1950s the problem of organising mass language teaching for large masses of population came into question among the representatives of international pedagogical community. Thus, at the international conference, which was held in Paris in 1959, with the participation of the Council of Europe's members, it was defined that the work towards providing citizens with the conditions for mastering foreign languages should have been the program of joint action of all the member states of the European community. That program resulted in establishing the Centre of Researching and Studying the Dissemination of French (Centre de Recherches et d'Etudes pour la Diffusion du Français) and also in the session of the spokesmen for the Cultural Affairs Committee of the Council of Europe, which was organised in Strasbourg in 1960, and was dedicated to the problem of coordinating the strategies of adult foreign language training on the basis of introducing upto-date self-instruction methods.

It is noteworthy that in that period the system of international educational exchange both for students and teachers was being actively introduced into the practice of 
foreign language self-instruction at the level of higher schools and research institutes. That gave impetus to the dynamic development of the tandem method of foreign language learning, which was proposed as far back as in the $16^{\text {th }}$ century, but, despite its effectiveness, did not find broad application in those days. In order to systematise and generalise the theoretical and practical aspects of tandem method J. Wolff elaborated the methodological grounds of its using. That enabled regulating cooperation of tandempartners initially in the context of Spanish-German language interchange, and afterwards the methodological base for all the European languages was created.

At the end of 1960 s the development of international relations, tourism, migration and internationalisation of business were the factors of not only widespread systemic foreign language studying, but also of a surge of interest in learner autonomy and independent acquiring knowledge in foreign languages. To confirm this, it is relevant to mention H. Holec's viewpoint, who asserted that language education served as the link with global economy, and linguistic skills were one of the forms of economic capital (Holec, 1980). In addition to that a lot of researchers of that time (J. Johnstone, R. Rivera, A. Tough, etc.) substantiated that self study had distinctive excellence as the most effective form of both learning activities and self-development of the personality.

Considerable theoretical insights and practical experience in the sphere of foreign language self-instruction in 1970-80s were a driving force for forming and developing linguistic self-education, in particular, thanks to marking out the concept "autonomous learning" into a separate pedagogical category, which was installed in the pan-European standard of language education in the shape of the main educational goal and component of foreign language curricula.

It should be emphasised that the conception of autonomous foreign language learning was initially worked out solely in the context of the need for teaching adults languages for specific purposes within the scope of The Council of Europe's Modern Languages Project. And some timer later that problem was embodied in high and higher school, which provided the base for conducting numerous researches in the sphere of lifelong learning in accordance with the Council of Europe's programmes, in particular, at the premises of the Centre of Language Education and Research (Centre de Recherches et d'Applications Pédagogiques en Langues), founded in the University of Nancy, France, in 1971. Among the most progressive activity areas of the Centre in those days there was launching a self-access centre, where all visitors had a free access to authentic learning materials. The idea of founding such centres of foreign language self studying quickly became popular, and later such centres were established in a number of European and Asian countries as well as in the UK, the USA, Canada, etc. In view of this, it is worth mentioning a pedagogically valuable and useful experience of Japan and South Korea, where a great attention is still paid to the problem of tutorship, which is based on the principles of pedagogical support. In these countries there operate extensive networks of self-access language centres, in which visitors can receive assistance, (e.g. concerning orientation in a wide variety of information resources and solving possible problems while studying), from the consultants, who have taken special training programmes.

The analysis of source materials has shown that at the end of 1980 s one could observe a noticeable reduction of research initiatives on the issue of autonomous foreign language learning. One of the reasons for that was that the representatives of academic community never came to a unanimous conclusion on the essence of the pedagogical category "learner autonomy", despite the presence of a comparatively precise definition of 
this notion, which was once presented by $\mathrm{H}$. Holec and then reconsidered by D. Little. According to these authors learner autonomy had the form of the person's ability of independent decision-making and performing activities from the perspective of critical reflection (Holec, 1990; Little, 1991).

The necessity of solving a great number of contradictions concerning the definition of the term "learner autonomy", to a certain extent, acted as a spur to holding in 1986 by H. Long the first International Self-Directed Learning Symposium, which, since then, has been organised annually and still serves as a forum for discussing the latest scientific and methodological developments in the theory and practice of autonomous education. Moreover, almost twenty years later, in 2004, a specialised International Journal of Self-Directed Learning was founded, which focused solely on that issue; and in 2005 the International Society for Self-Directed Learning was created.

In 1980-90s the researches detected that it was essential to provide students with special training for foreign language self-instruction, as in the course of independent task completion, students only gain an ability of being responsible and attentive while doing the tasks. The scientists concluded it was not enough to speak about learner autonomy, because the latter also presupposed the formed skills of goal setting, planning, performing and reflecting one's own learning activities. As a result, there arose a necessity of elaborating methodological fundamentals of forming students' preparedness for linguistic selfeducation. The educators agreed that the key element of teaching students the technology of independent acquiring foreign language knowledge should have been the set of certain learning strategies, each of which would make it possible for them to gain the skills of reading, writing, listening and speaking. A. Wenden and J. Rubin were the first to define the notion "learning strategies" and proposed their classification (Wenden, 1987).

Studying the recent publications on the research problem has revealed that some educators of Oriental countries (H.-C. Hsieh, O. Tamer, etc.) pose the question concerning the "globality" of learner autonomy, that is, whether this "exclusively Western invention" is equally effective in other countries with completely different mentalities. N. Aoki, W. Littlewood, R. Smith have stipulated that a developed preparedness for learner autonomy is a new psychological formation of metaphysical level, which depends solely on individual psychical peculiarities of the person and therefore is a supranational phenomenon, that is, exists beyond the context of national cultures (Aoki, 1999; Littlewood, 2001). In spite of the relative reasonableness of the above-mentioned statement, we consider that in this issue national traditions play a significant role, as the students' attitude to autonomy, e.g. through the lens of millennial traditions of education in the spirit of the classical principles of Islam or Confucianism, cardinally differs from the views of their Western colleagues, who are brought up on the ideas of freedom and democracy.

It should be said that at the end of the $20^{\text {th }}$ and beginning of the $21^{\text {st }}$ centuries along with theoretical developments there were constructive practical improvements in the field of linguistic self-education. Both in Western and Oriental higher schools self-educational activities became an integral part of learning process and got the equal status with the traditional forms of academic studies, namely, lectures, seminars, practical and laboratory works. At the universities in the USA, Germany, France, Sweden, etc. doing research work underlies the system of education, which favours the development of students' autonomy.

A number of researchers (H. De Vos, D. Louw, C. Ohlson, C. Suey, J. Szente, R. Varley) suggest to broaden the range of courses, which students can select while studying at university, by means of conducting different short-term trainings and seminars 
aimed at acquiring the skills of self-education. For instance, at the University of Central Florida, the USA, students have an opportunity to boost their own self-esteem and selfefficacy with the help of a special programme for teaching positive goal setting. At the University of Sheffield, the UK, at psychological trainings students receive "augmenting self-help materials" which contain not only theoretical information and practical recommendations concerning self-management in difficult situations, but also reflective tasks on defining your own psychological profile as well as fieldwork aimed at training selfregulation and supporting self-appraisal. The augmenting self-help materials are usually supplemented by the tasks of making "if-then plans", within which the students are offered to present the models of possible practical application of the knowledge which they have gained in the course of studying. Furthermore, it is recommended to use up-to-date methods in the university learning process, such as the methods of stimulating reflective activities; developing the skills of self-analysis, self-criticism; forming self-concept, etc. Among such methods, it is relevant to mention the methods of neuro-linguistic programming and psychosynthesis; method of verbalising the results of reflection; method of analysing concrete situations (cases); method of psychological diagnostics; training methods, such as trainings aimed at actualising cognitive motives; reflecting the actions performed; relieving inner conflicts; teaching learning strategies. As for linguistic self-educational activities, Western European scientists propose to use such methods as keeping diaries and reflective web-blogs; completing specific reflective tasks in writing, which subsequently are to be discussed in the form of classroom-based or online discussions, etc.

\section{CONCLUSIONS}

Thus, the conducted retrospective analysis of forming the phenomenon "linguistic self-education" has shown that essence and forms of this pedagogical category were constantly changing depending on certain political, economic and social factors which acted as stimuli for its evolving and spreading. The content of the aforementioned phenomenon was also defined by the logic of the development of education in whole. This problem is still actively researched because the formed preparedness for linguistic selfeducation of students is the pledge of their free orienting in the dynamic conditions of postindustrial epoch which is characterised by quick obsolescence of knowledge, all-round informatisation, transparency of borders, and high degree of social mobility; as well as by tough competition on the job market.

Within the further researches we are planning to work out a model of forming the students' preparedness for linguistic self-education, taking into account the wide pedagogical experience of the past.

\section{REFERENCES}

1. Aoki, N., Smith, R. (1999). Learner Autonomy in Cultural Context: the Case of Japan. In: Crabbe, D. \& Cotterall, S. (Eds.). Learner Autonomy in Language Learning: Defining the Field and Effecting Change. Frankfurt am Main : Peter Lang GmbH International, pp. 19-27.

2. Holec, H. (1980). Learner Training: Meeting Needs in Self-Directed Learning. In: Altman, H. B. \& James, C. V. (Eds.). Foreign Language Learning: Meeting Individual Needs. Oxford : Pergamon, pp. 30-45.

3. Holec, H. (1990). Qu'est-ce qu'apprendre a apprendre [What does It Mean to Learn]. Retrieved 28.02.2017 from : http://atilf.fr/IMG/pdf/melanges/6holec-3.pdf. 
4. Little, D. (1991). Learner Autonomy 1: Definitions, Issues and Problems. Dublin : Authentic Language Learning Resources Ltd, $62 \mathrm{p}$.

5. Littlewood, W. (2001). Students' Attitudes to Classroom English Learning: a Cross-Cultural Study. Language Teaching Research, No 5 (1), pp. 3-28.

6. Onions, C. T. (1944). Shorter Oxford English Dictionary. Oxford : Oxford University Press, $24 \mathrm{p}$.

7. Wenden, A. (1987). How to Be a Successful Language Learner: Insights and Prescriptions from L2 Learners. In: Wenden, A. \& Rubin, J. (Eds.), Learner Strategies in Language Learning. Cambridge : Prentice-Hall, pp. 103-116. 